Ciência Florestal, Santa Maria, v. 22, n. 4, p. 725-738, out.-dez., 2012

ISSN 0103-9954

\title{
BIOMARCADORES DERIVADOS DE PLANTA E DE MICRORGANISMOS EM SOLOS DE TABULEIROS COSTEIROS CULTIVADOS COM EUCALIPTO E ACÁCIA
}

\author{
PLANT-AND MICROBIAL-DERIVED BIOMARKERS IN COASTAL PLAIN SOILS CULTIVATED \\ WITH EUCALYPT AND ACÁCIA
}

\author{
Rodinei Facco Pegoraro ${ }^{1}$ Ivo Ribeiro da Silva ${ }^{2}$ Roberto Ferreira de Novais ${ }^{3}$ \\ Nairam Felix de Barros ${ }^{4}$ Sebastião Fonseca ${ }^{5}$
}

\begin{abstract}
RESUMO
Alterações no sistema de manejo pelo cultivo de diferentes povoamentos florestais e a utilização de rotação de culturas podem levar a alterações na qualidade da matéria orgânica do solo (MOS) e deposição de resíduos vegetais. O presente estudo avaliou o estádio de decomposição e a contribuição de compostos de origem vegetal e microbiana para a MOS por meio de biomarcadores, tais como: fenóis derivados de lignina, carboidratos e aminoaçúcares em monocultivos do Eucalyptus urograndis (clone do Eucalyptus urophylla S. T. Blake x Eucalyptus grandis W. Hill ex Spreng) de ciclo curto (sete anos), sistemas de cultivo de rotação de acácia (Acacia mangium Willd.) após monocultivo de eucalipto, monocultivo de eucalipto de ciclo longo (24 anos) e mata nativa (Mata Atlântica) como condição original de solo do litoral Norte do Espírito do Santo. Para tanto, foram estimados nas amostras de solo e serapilheira os teores de C orgânico total (COT), $\mathrm{N}$ total (NT), teores de fenóis derivados de lignina (VSC), carboidratos e aminoaçúcares derivados da atividade microbiana no solo e, as relações ácidos e aldeídos dos grupamentos vanilil $\left((\mathrm{Ac} / \mathrm{Al})_{\text {Vanilii }}\right)$ e siringil $\left((\mathrm{Ac} / \mathrm{Al})_{\text {Siringil }}\right)$ da lignina, relação hexoses/pentoses $(\mathrm{H} / \mathrm{P})$ dos carboidratos e, relações glucosamina/ácido murâmico (Gluc/Mur.) e glucosamina/galactosamina (Gluc/Gal) dos aminoaçúcares. Os resultados indicaram que na serapilheira do monocultivo de eucalipto de ciclo curto houve maior deposição da matéria seca, teor de lignina (VSC) e carboidratos, relação C/N e VSC/N; Semelhante proporção de resíduos grossos, resíduos finos e teor de $\mathrm{C}$ e, menor teor de $\mathrm{N}$, comparado àquela sob rotação de acácia. No solo, o cultivo de acácia aumentou os teores de $\mathrm{C}, \mathrm{N}$ e carboidratos, aumentou a relação ácido/aldeído do grupamento vanilil da lignina e a relação glucosamina/ácido murâmico dos aminoaçúcares derivados da atividade microbiana. O aumento do tempo de cultivo do eucalipto (24 anos) incrementou o teor de $\mathrm{C}$ e reduziu a relação VSC/N na MOS em comparação ao monocultivo de eucalipto de ciclo curto, e apresentou teor de $\mathrm{C}$ e $\mathrm{N}$ inferiores àqueles observados no solo de acácia e mata nativa. A menor relação ácidos/ aldeídos (Ac/Al) dos fenóis derivados de lignina no solo cultivado com eucalipto (de curto e longo ciclo) indica que a MOS encontra-se em estádio menos avançado de decomposição do que no solo cultivado com acácia, e naquele de mata nativa. Nos solos de acácia, seguido por aquele de eucalipto, a maior relação glucosamina/ácido murâmico sugere maior participação de fungos na comunidade microbiana, enquanto nas áreas de mata nativa e eucalipto de ciclo longo há mais abundância de compostos derivados de bactérias. Neste sentido, observou-se a recuperação na qualidade do solo cultivado com eucalipto de ciclo longo e rotacionado com acácia em relação ao monocultivo de eucalipto de ciclo curto.
\end{abstract}

Palavras-chave: lignina; carboidratos; aminoaçúcares; matéria orgânica do solo.

1. Engenheiro Agrônomo, Dr., Professor do Departamento de Ciências Agrárias, Universidade Estadual de Montes Claros, Av. Reinaldo Viana, Bico da Pedra, s/n., CEP 39440-000, Janaúba (MG). rodinei.pegoraro@unimontes.br Bolsista da FAPEMIG

2. Engenheiro Agrônomo, PhD., Professor do Departamento de Solos, Universidade Federal de Viçosa, Av. Peter Henry Rolfs, s/n., Campus Universitário, CEP 36570-000, Viçosa (MG). ivosilva@ufv.br

3. Engenheiro Agrônomo, PhD., Professor do Departamento de Solos, Universidade Federal de Viçosa, Av. Peter Henry Rolfs, s/n., Campus Universitário, CEP 36570-000, Viçosa (MG). Bolsista do CNPq. rfnovais@ufv.br

4. Engenheiro Florestal, PhD., Professor do Departamento de Solos, Universidade Federal de Viçosa, Av. Peter Henry Rolfs, s/n., Campus Universitário, CEP 36570-000, Viçosa (MG). Bolsista do CNPq. nfbarros@ufv.br

5. Engenheiro Florestal, MSc., Pesquisador da Fibria Celulose S.A., Caixa Postal 331011, CEP 29197-000, Aracruz (ES).sf@fibria.com.br

Recebido para publicação em 2/09/2010 e aceito em 19/08/2011

Ci. Fl., v. 22, n. 4, out.-dez., 2012 


\begin{abstract}
Changes in the management systems for the cultivation of different forest stands and the use of species rotation can lead to alterations in the quality of soil organic matter (SOM) and plant residue deposition. This study evaluated the stage of decomposition and the contribution of plant and microbial origin for SOM through biomarkers, such as lignin-derived phenols, carbohydrates and amino sugars in continuous shortrotation eucalypt (Eucalyptus urophylla $\mathrm{x}$ Eucalyptus grandis hybrid) (seven years) compared to a rotation system including acacia (Acacia mangium Willd.) after short-rotation eucalypt; and long-rotation eucalypt (24 years). A native vegetation (Atlantic Forest) was used as a reference for the original site condition representative for the northern coast of Espírito Santo state. To do so, we estimated the content of total organic C (TOC), total N (TN) and the contents of lignin-derived phenols (VSC), the carbohydrates and the amino sugars derived from soil microorganisms, and acids/aldehyde ratio of groups vanilil ((Ac/Al $\left.)_{\text {vanili }}\right)$ and syringyl $\left((\mathrm{Ac} / \mathrm{Al})_{\text {syringyl }}\right)$ of the lignin, hexoses/pentoses $(\mathrm{H} / \mathrm{P})$ ratio of carbohydrates, besides glucosamine/ muramic acid (Gluc/Ac. Mur) and glucosamine/galactosamine (Gluc/Gal) ratios for soil and litter samples. The results indicated that litter of the continuous short-rotation eucalypt has greater dry mass, lignin (VSC) and carbohydrates contents, $\mathrm{C} / \mathrm{N}$ and $\mathrm{VSC} / \mathrm{N}$ ratios; a similar proportion of coarse litter to fine litter and $\mathrm{C}$ content, but a lower $\mathrm{N}$ content in comparison to the species rotation system that includes the leguminous acacia. In the soil, acacia cultivation increases $\mathrm{C}, \mathrm{N}$ and carbohydrates content, widened the acid/aldehyde ratio of vanilil groups of lignin and the glucosamine/muramic acid ratio of amino sugars derived from microbial activity. The longer rotation of eucalypt (24 years) increased $\mathrm{C}$ content and decreased the VSC/N ratio in SOM compared to the continuous short-rotation eucalypt, but still having $\mathrm{C}$ and $\mathrm{N}$ content lower than in soil of acacia and native forest. The smallest Ac/Al ratio of lignin-derived phenols in soils cultivated with eucalypt (in long and short-rotation) indicates that the SOM is in less advanced stage of decomposition (humification) than in the soil cultivated with acacia, and that under native forest. In soils under acacia, followed by that of short-rotation eucalypt, the higher glucosamine/muramic acid ratio suggested a greater contribution of fungi in SOM cycling, whereas in the native forest and long-rotation eucalypt there is greater abundance of bacteria-derived compounds. Overall, the results indicate that there was a recovery in the quality of the soils cultivated with eucalypt for a longer rotation and also with acacia in relation to the continuous short-rotation eucalypt.
\end{abstract}

Keywords: lignin; carbohydrates; amino sugar; soil organic matter.

\section{INTRODUÇÃO}

A manutenção do estoque de carbono no solo em monocultivos florestais tem sido uma preocupação constante de empresas florestais, produtores e pesquisadores brasileiros, especialmente em monocultivos de eucalipto (Pegoraro et al., 2011a), devido à dificuldade de conversão de resíduos vegetais em matéria orgânica do solo (MOS). Técnicas silviculturais, como o cultivo de consórcio de acácia (Acacia mearnsi), uma leguminosa que fixa nitrogênio atmosférico com o eucalipto, têm demonstrado maior eficácia em aumentar os conteúdos de $\mathrm{C}$ e $\mathrm{N}$ no solo, possivelmente por estreitar a relação lignina/ $\mathrm{N}$, aumentar a labilidade da serapilheira e a presença de compostos orgânicos derivados da atividade microbiana no solo, favorecendo a estabilização da MOS nativa (FORRESTER et al.,
2006)

Estima-se que o incremento de compostos orgânicos derivados da atividade microbiana no solo favoreça a formação de complexos organominerais, a agregação do solo e o aumento do tempo de residência do C na MOS (BAILEY et al., 2002; SIMPSON et al., 2004). Indicadores da contribuição microbiana para a origem da MOS podem ser estimados pela presença de polímeros de pentoses (arabinose (ara) + xilose (xil)) e, a contribuição vegetal pode ser estimada pela presença de polímeros de hexoses (galactose (gal) + manose (man)) (AMELUNG et al., 1999). Ainda, pode-se identificar quais grupos de microrganismos (fungos/bactérias) mais contribuem para formação da MOS diante da presença dos aminoaçúcares glucosamina, derivados tipicamente da atividade fúngica, do ácido murâmico e da galactosamina, derivados da atividade bacteriana (ZHANG et 
al., 1998; SOLOMON et al., 2002; MÖLLER et al., 2002; SIMPSON et al., 2004; GLASER et al., 2004). Assim, é possível estabelecer relações (ex. glucosamina/ácido murâmico) que podem servir como indicadores da contribuição relativa fúngica e bacteriana para a MOS (ZHANG et al., 1998; AMELUNG et al., 1999; LIANG et al., 2007).

Resíduos de plantas florestais têm consideráveis teores de lignina na parede celular (SUHAS e CARROTT, 2007, PEGORARO et al., 2010; PEGORARO et al., 2011b; PILLON et al., 2011). A lignina é considerada o componente da serapilheira com menor taxa de decomposição devido à maior complexidade estrutural (HEIM e SCHMIDT, 2007), e apresenta significativa contribuição para o compartimento de C estável no solo (STEVENSON, 1994; RASSE et al., 2006). Um dos nutrientes que mais interfere no processo de estabilização do $\mathrm{C}$ em formas aromáticas/lignina no solo é o N. O cultivo de espécies florestais fixadoras de $\mathrm{N}_{2}$, como a acácia, em consórcio com o eucalipto, contribui para o incremento de $\mathrm{N}$ no solo (GARAY et al., 2004), podendo reduzir a habilidade competitiva de fungos que são responsáveis pela decomposição da lignina (FOG, 1988), suprimir a formação de enzimas que fazem sua quebra (CARREIRO et al., 2000) e, reagir com resíduos de lignina (e outros compostos fenólicos) formando complexos de alta resistência à degradação microbiana (STEVENSON, 1994). Consequentemente, resíduos de planta (serapilheira) com alto teor de lignina podem aumentar a formação e a estabilização de $\mathrm{C}$ em formas mais recalcitrantes no solo em resposta à maior presença de N. Isso tem implicações importantes, pois aumenta o sequestro de $\mathrm{C}$, mas pode reduzir a disponibilidade de N (OLK et al., 2004). O grau de oxidação/alteração da lignina, e, consequentemente, sua estabilização, podem ser identificados pela abundância de grupamentos ácidos e aldeídos no solo (relação Ac/Al), sendo o estado de degradação/oxidação proporcional ao valor obtido para a relação $\mathrm{Ac} / \mathrm{Al}$ dos grupamentos siringil e vanilil (OTTO e SIMPSON, 2006).

O presente estudo avaliou o estádio de decomposição e a contribuição de compostos de origem vegetal e microbiana para a MOS, por meio da presença de: fenóis derivados de lignina, carboidratos e aminoaçúcares no solo e serapilheira de monocultivos de eucalipto de ciclo curto em comparação a sistemas de cultivo de rotação de acácia, monocultivo de eucalipto de ciclo longo e mata nativa, como condição original de solo do litoral Norte do Espírito do Santo.

\section{MATERIAL E MÉTODOS}

O trabalho foi conduzido com amostras de serapilheira e solo do município de AracruzES, nas coordenadas geográficas $19^{\circ} 48^{\prime} \mathrm{S}$ e $40^{\circ} 17^{\prime} \mathrm{W}$. O clima da região é do tipo Aw, segundo a classificação de Köppen (OMETTO, 1981), com temperatura e precipitação pluvial média anual de, respectivamente, $23{ }^{\circ} \mathrm{C}$ e $1.400 \mathrm{~mm}$ ano ${ }^{-1}$. O local representa uma microbacia típica da região dos Tabuleiros Costeiros. O solo foi caracterizado como Argissolo Amarelo fase floresta tropical subperenifólia textura média sobre argilosa, derivado do grupo Barreiras (EMBRAPA, 2006).

Para a realização do trabalho foram selecionadas áreas onde se cultivava o eucalipto e, ao lado, existiam manejos e usos alternativos do solo, que foram: floresta nativa (Mata Atlântica)MN, eucalipto de ciclo longo (24 anos)-E24, acácia (Acacia mangium, 14 anos)-A após monocultivo de eucalipto e eucalipto de ciclo curto (sete anos)-E7. Até a época da coleta das amostras de solo as áreas (talhões) de eucalipto de ciclo curto (E7) selecionadas já tinham sido cultivadas por 28 anos (quatro rotações) com esta cultura.

Previamente ao último plantio de eucalipto, o solo foi preparado mediante gradagem ("bedding") para que os resíduos da colheita fossem incorporados no solo na direção da linha de cepas (tocos) do cultivo anterior e, em seguida, foi coveado, plantado e fertilizado manualmente com $100 \mathrm{~g} \mathrm{cova}^{-1}$ de adubo formulado NPK 6-30-6.

O último plantio de eucalipto de ciclo curto foi realizado em 1998, com plantas provenientes de híbridos clonais de Eucalyptus grandis x Eucalyptus urophyla, cultivados em sistema de reforma e, espaçamento entre plantas de $3 \times 3 \mathrm{~m}$. Após 90 dias do plantio, as plantas receberam $350 \mathrm{~kg} \mathrm{ha}^{-1} \mathrm{de}$ fosfato natural e, no final do primeiro ano, mais 160 $\mathrm{kg} \mathrm{ha}^{-1}$ de NPK 6-30-6.

$\mathrm{O}$ talhão de E24 foi desbastado ao longo dos anos até chegar ao espaçamento atual de $9 \mathrm{x}$ $9 \mathrm{~m}$. Nesse povoamento, há um sub-bosque que é controlado, frequentemente, por meio de roçada manual. O plantio das mudas de A. mangium em ciclo com eucalipto foi realizado após o corte do eucalipto no ano de 1990, em área já cultivada com eucalipto por duas rotações, com manejo de adubação semelhante ao adotado para o monocultivo de eucalipto de ciclo curto. 
Nessas áreas, foram selecionados talhões com aproximadamente 10 hectares e coletadas amostras de serapilheira e solo com estrutura não preservada e preservada, na linha de plantio do cultivo de eucalipto de ciclo longo, do ciclo curto e da acácia e, em área total na mata nativa. Para o solo com estrutura não preservada foram coletadas três amostras compostas na camada de $0,00-0,10 \mathrm{~m}$, sendo cada amostra proveniente de seis amostras simples e, para o solo com estrutura preservada foram coletadas três amostras simples na camada de 0,00-0,10 m, para cada área de cultivo.

As amostras de solo foram coletadas na época chuvosa (janeiro/fevereiro de 2004). O povoamento de eucalipto de ciclo curto estava no final do ciclo (seis a sete anos) e, aquele de ciclo longo e o cultivo de acácia estavam, respectivamente, com pelo menos 24 e 14 anos de cultivo. Depois de coletadas, as amostras de solo foram imediatamente secas ao ar, destorroadas, passadas em peneira com malha de $2 \mathrm{~mm}$, homogeneizadas e subamostras foram retiradas para caracterização física e química (Tabela 1), segundo EMBRAPA (1997): Para determinação do $\mathrm{pH}$ em $\mathrm{H}_{2} \mathrm{O}$ foi observada a relação 1:2,5 de solo:solução; o P e K disponíveis foram extraídos por meio da solução Mehlich 1 e quantificados, respectivamente em Espectrofotômetro UV-VIS e

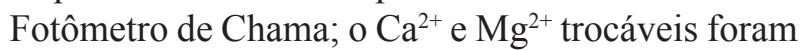
extraídos com solução $\mathrm{KCl}-1 \mathrm{~mol} \mathrm{~L}^{-1} \mathrm{e}$ dosados em Espectrofotômetro de Absorção Atômica; a acidez potencial $(\mathrm{H}+\mathrm{Al})$ foi extraída com acetato de cálcio $0,5 \mathrm{~mol} \mathrm{~L}^{-1}$ a pH 7,0 e, dosada por titulação com a solução hidróxido de sódio $0,025 \mathrm{~mol} \mathrm{~L}^{-1}$; a textura do solo foi determinada pelo método da pipeta e a areia retida na peneira foi fracionada em areia fina $(0,05-0,20 \mathrm{~mm})$ e areia grossa $(0,20-2,00 \mathrm{~mm})$; e a densidade do solo foi determinada pelo "Método do anel volumétrico", utilizando-se um anel (cilindro) com dimensões correspondentes a $50 \mathrm{~mm}$ de diâmetro e 2,65 mm de altura.

A serapilheira na superfície do solo foi amostrada no momento da coleta das porções de solo, da seguinte forma: dentro de cada área dos tratamentos selecionados foram identificados quatro pontos aleatoriamente, lançando-se um gabarito com $0,25 \mathrm{~m}^{2}$ de área $(0,5 \times 0,5 \mathrm{~m})$. A serapilheira coletada era composta por galhos, cascas e folhas. No eucalipto de ciclo curto e na acácia a coleta foi feita imediatamente após o corte das árvores, ao final do ciclo. Após a coleta, as amostras de serapilheira foram secadas em estufa a $65{ }^{\circ} \mathrm{C}$ durante 72 horas para determinação da matéria seca e caracterização bioquímica.

Nas amostras de solo e serapilheira efetuaram-se análises de C orgânico total (COT), $\mathrm{N}$ total (NT), teores de fenóis derivados de lignina (VSC), carboidratos e aminoaçúcares derivados da atividade microbiana no solo. Por meio dessas análises, obtiveram-se as relações ácidos e aldeídos dos grupamentos vanilil $\left((\mathrm{Ac} / \mathrm{Al})_{\text {Vanilii }}\right)$ e siringil $\left((\mathrm{Ac} / \mathrm{Al})_{\text {Siringil }}\right)$ da lignina, relação hexoses/pentoses (H/P) dos carboidratos e, relações glucosamina/ ácido murâmico (Gluc/Mur.) e glucosamina/ galactosamina (Gluc/Gal) dos aminoaçúcares.

\section{Determinação do carbono orgânico total e nitrogênio total do solo e na serapilheira}

Amostras de solo (TFSA) foram trituradas e passadas em peneira de 100 mesh $(0,149 \mathrm{~mm})$ para determinação de COT pelo método de oxidação via úmida, com aquecimento externo (YEOMANS e BREMNER, 1988). O NT foi determinado por

TABELA 1: Características químicas e físicas dos solos de mata nativa (MN), povoamento de eucalipto de ciclo longo - 24 anos (E24), acácia em rotação com eucalipto (A) e eucalipto de ciclo curto sete anos (E7).

TABLE 1: Soil chemical and physical characteristics of native forest (MN), eucalyptus plantation with long-cycle - 24 years (E24), acacia in rotation with eucalyptus (A) and eucalyptus short-cycle - seven years (E7).

\begin{tabular}{lccccccccccc}
\hline Cultivo & $\mathrm{pH}$ & $\mathrm{Ca}^{2+}$ & $\mathrm{Mg}^{2+}$ & $\mathrm{H}+\mathrm{Al}$ & $\mathrm{P}$ & $\mathrm{K}$ & $\begin{array}{c}\text { Areia } \\
\text { grossa }\end{array}$ & $\begin{array}{c}\text { Areia } \\
\text { fina }\end{array}$ & Silte & Argila & $\begin{array}{c}\text { Densidade } \\
\text { (nN }\end{array}$ \\
\hline E24 & 4,4 & 0,52 & 0,31 & 0,89 & 3,4 & 32 & 57 & 15 & 5 & 23 & 1,4 \\
A & 4,8 & 0,84 & 0,36 & 0,68 & 2,3 & 21 & 53 & 16 & 4 & 27 & 1,4 \\
E7 & 4,5 & 1,07 & 0,29 & 0,58 & 5,7 & 35 & 51 & 16 & 5 & 28 & 1,4 \\
\hline
\end{tabular}


destilação após digestão sulfúrica (BATAGLIA et al., 1983). Após preparo da amostra de serapilheira quantificou-se os teores de COT e NT por combustão via seca em analisador Perkin Elmer CHNS/O 2400.

\section{Oxidação da lignina (VSC) com $\mathrm{CuO}$ e análise dos derivados por cromatografia líquida}

A degradação termoquímica da lignina contida nas frações da MOS foi realizada pelo método de oxidação com $\mathrm{CuO}$ em micro-ondas (GOÑI e MONTGOMERY, 2000). $\mathrm{O}_{2}$ das soluções de trabalho contendo $\mathrm{NaOH} 2 \mathrm{~mol} \mathrm{~L}^{-1}$ foi eliminado por meio de injeção de $\mathrm{N}_{2}$ por borbulhamento durante $12 \mathrm{~h}$. Amostras de solo e resíduos vegetais (passados na peneira de 60 mesh) foram acondicionadas em tubos de teflon contendo de 2 a $5 \mathrm{mg}$ de C orgânico, juntamente com $500 \mathrm{mg}$ de $\mathrm{CuO}, 50 \mathrm{mg}$ de sulfato ferroso amoniacal e 15 $\mathrm{mL}$ de $\mathrm{NaOH} 2 \mathrm{~mol} \mathrm{~L}^{-1}$. A mistura foi aquecida em micro-ondas, em ambiente de $\mathrm{N}_{2}$, com pressão de trabalho entre 60 e 70 psi durante 90 min., com esta pressão atingiu-se temperatura de $150{ }^{\circ} \mathrm{C}$. Após a mistura ter esfriado, esta foi transferida para tubos de centrífuga de $50 \mathrm{~mL}$ e centrifugada a $1.844 \mathrm{xg}$ por $10 \mathrm{~min}$. Esta etapa foi repetida por mais duas vezes, adicionando-se $5 \mathrm{~mL}$ de $\mathrm{NaOH} 1 \mathrm{~mol} \mathrm{~L}^{-1}$ por repetição. $\mathrm{O}$ sobrenadante alcalino foi acidificado para $\mathrm{pH} 1$ com adição de, aproximadamente, $4 \mathrm{~mL}$ de $\mathrm{HCl}$ concentrado. Para capturar os monômeros de lignina, misturaram-se $6 \mathrm{~mL}$ de acetado de etila com o sobrenadante em erlenmeyer de vidro. A fase orgânica foi transferida para tubos de vidro, repetindo-se a etapa por mais duas vezes. Possíveis resquícios de água foram removidos com adição de $\mathrm{Na}_{2} \mathrm{SO}_{4}$. Então, solidificou-se a amostra em concentrador a vácuo $\left(45^{\circ} \mathrm{C}\right)$. As amostras foram redissolvidas em $5 \mathrm{~mL}$ de água ultrapura com o auxílio de sonda de ultrassom para facilitar a solubilização dos compostos em água. Depois de ser passada em filtro de nylon de 0,45 $\mu \mathrm{m}$, pipetou-se $0,5 \mathrm{~mL}$ desta solução aquosa para frascos do amostrador automático e, então, se fez a identificação e quantificação dos derivados de lignina por cromatografia iônica (DX 600 - Dionex, Sunnyvale, CA, EUA).

Os fenóis quantificados desta oxidação foram os monômeros do grupo vanilil (V), siringil (S) e cinamil (C). Os monômeros dos grupos $\mathrm{V}$ e $\mathrm{S}$ foram calculados de correspondentes aldeídos, cetonas e ácidos carboxílicos: $\mathrm{V}=$ vanilin + acetovanilona + ácido vanílico; $\mathrm{S}=$ siringaldeído + acetosiringona + ácido siríngico. Os monômeros do grupo $\mathrm{C}$ foram derivados do somatório de ácido p-coumárico e ácido ferúlico. Considerouse o VSC ( $\mathrm{g} \mathrm{kg}^{-1}$ de serapilheira e $\mathrm{mg} \mathrm{kg}^{-1}$ de solo) como o somatório destes três grupos, os quais corresponderam ao teor de lignina oxidada com $\mathrm{CuO}$ em micro-ondas. Usando as relações de massa entre ácidos carboxílicos (Ac) e aldeídos (Al) nos grupos vanilil (V) e siringil (S), expressos respectivamente como $(\mathrm{Ac} / \mathrm{Al})_{\mathrm{V}}$ e $(\mathrm{Ac} / \mathrm{Al})_{\mathrm{S}}$, estimou-se o grau de decomposição (oxidação) da lignina (HEDGES e ERTEL, 1982; OTTO e SIMPSON, 2006).

\section{Separação e quantificação de carboidratos}

Subamostras de solo (100 mg) e resíduos vegetais $(20 \mathrm{mg})$ foram moídas em moinho de bola, peneiradas (60 mesh), pesadas e acondicionadas em tubos de ensaio; adicionaram-se $800 \mu \mathrm{L}$ de $\mathrm{H}_{2} \mathrm{SO}_{4} 6 \mathrm{~mol} \mathrm{~L}^{-1} \mathrm{e}$, então, as amostras foram homogeneizadas por meio de agitação manual. Esperaram-se $30 \mathrm{~min}$ e procedeu-se diluição das amostras por meio de adição de 4,2 $\mathrm{mL}$ de água ultrapura com o intuito de atingir uma concentração final de $1 \mathrm{~mol} \mathrm{~L}^{-1}$ de $\mathrm{H}_{2} \mathrm{SO}_{4}$. As amostras foram tampadas com papel laminado, vedadas com cordão de borracha e aquecidas em autoclave por $30 \mathrm{~min}$ à temperatura de $121{ }^{\circ} \mathrm{C}(104 \mathrm{kPa})$. Esperou-se que as amostras esfriassem à temperatura ambiente para prosseguir com a centrifugação $(1844 \mathrm{xg})$ por $10 \mathrm{~min}$, separando-se o sobrenadante do resíduo. Este procedimento foi repetido por mais duas vezes com a adição de $1 \mathrm{~mL}$ de água ultrapura, objetivando a máxima recuperação do conteúdo de compostos orgânicos solúveis do resíduo. Segundo Martens e Loeffelmann (2002), este procedimento não consegue extrair totalmente os monômeros de celulose e hemicelulose dos resíduos vegetais. Portanto, conforme sugerido por esses autores, para melhorar essa taxa de recuperação levaram-se os resíduos da primeira extração à estufa $\left(60^{\circ} \mathrm{C}\right)$ até a secagem da amostra. Após, adicionaram-se $300 \mu \mathrm{L}$ de $\mathrm{H}_{2} \mathrm{SO}_{4} 18 \mathrm{~mol} \mathrm{~L}^{-1}$ e esperaram-se 30 min para, novamente, realizar a diluição da solução com 3,6 $\mathrm{mL}$ de água ultrapura, atingindo a concentração final de $1 \mathrm{~mol} \mathrm{~L}^{-1}$ de $\mathrm{H}_{2} \mathrm{SO}_{4}$. $\mathrm{O}$ frasco foi vedado e autoclavado por $30 \mathrm{~min}$ à temperatura de $121^{\circ} \mathrm{C}$ $(104 \mathrm{kPa})$. Quando a solução retornou à temperatura ambiente ela foi centrifugada (1.844 xg) por $10 \mathrm{~min}$ e, então, retirou-se o sobrenadante. Este passo foi repetido por mais duas vezes, adicionando-se $1 \mathrm{~mL}$ de água ultrapura antes de cada centrifugação. O sobrenadante da primeira fase foi misturado com o da segunda em tubos de $20 \mathrm{~mL}$ e diluído 100 
vezes. As amostras foram passadas em filtro de nylon de $0,45 \mu \mathrm{m}$ e, então, pipetou-se $0,5 \mathrm{~mL}$ para identificação e quantificação dos monômeros de carboidratos por cromatografia iônica.

\section{Separação e quantificação de aminoaçúcares}

Os aminoaçúcares glucosamina (Glc) e galactosamina (Gal), e o ácido murâmico (Mur) foram extraídos do solo conforme Zhang e Amelung (1996). Subamostras contendo, aproximadamente, $0,3 \mathrm{mg}$ de $\mathrm{N}$, juntamente com um padrão interno (myo-inositol), foram acondicionadas em tubos de vidro com tampa de teflon e hidrolisadas com $\mathrm{HCl}$ 6 mol L-1 a $105^{\circ} \mathrm{C}$ por $8 \mathrm{~h} \mathrm{em}$ ambiente de $\mathrm{N}_{2}$. O hidrolisado foi centrifugado $(1.844 \mathrm{xg})$ por $10 \mathrm{~min}$ $\left(4{ }^{\circ} \mathrm{C}\right)$. O sobrenadante foi transferido para tubos de vidro e concentrado sob vácuo a $40{ }^{\circ} \mathrm{C}$. A amostra foi redissolvida em $20 \mathrm{~mL}$ de água ultrapura e ajustou-se o pH da solução para 6,6-6,8 com KOH $0,4 \mathrm{~mol} \mathrm{~L}^{-1}$. Após neutralizar a solução com $\mathrm{KOH}$ para precipitar o $\mathrm{Fe}$, a mistura foi centrifugada, novamente, durante $15 \mathrm{~min}$ a $1.884 \mathrm{xg}\left(4{ }^{\circ} \mathrm{C}\right) \mathrm{em}$ tubos de centrífuga de $50 \mathrm{~mL}$. O sobrenadante foi concentrado e rediluído em $1 \mathrm{~mL}$ de água. As frações de aminoaçúcares do sobrenadante foram rapidamente congeladas. Após filtragem por membranas de nylon de 0,45 $\mu \mathrm{m}$, utilizou-se 0,5 $\mathrm{mL}$ da solução para identificação e quantificação dos aminoaçúcares por cromatografia iônica. Todo o sistema cromatográfico era controlado por meio do software Chromeleon (Dionex).

\section{Análise estatística dos resultados}

Os resultados foram analisados no programa estatístico SAEG 5.0 (FUNARBE, 1993). As médias dos tratamentos (três repetições para solo e quatro para serapilheira) foram comparadas por meio do teste de LSD de Fisher $(\mathrm{p}<5 \%)$ protegido (STEEL et al., 1997), ou seja, foram realizadas comparações múltiplas apenas quando o teste de $\mathrm{F}$ da análise de variância foi significativo $(\mathrm{p}<5 \%)$.

\section{RESULTADOS E DISCUSSÃO}

Os estoques de matéria seca na serapilheira foram maiores no povoamento de eucalipto de ciclo curto (sete anos) e no cultivo sob rotação de acácia (Tabela 2), justificado pelo aporte de resíduos da colheita, que não foi realizada nos outros dois ecossistemas (mata nativa e eucalipto de ciclo longo - 24 anos). Com a colheita das árvores, maior proporção de resíduos grossos foi alocado na serapilheira do cultivo de acácia e eucalipto de ciclo curto (respectivamente, $64 \%$ e $71 \%$ de resíduos grossos). De acordo com Mendham et al. (2004) e Lemma et al. (2007) estes resíduos grossos podem ser considerados ricos em celulose, hemicelulose e compostos lignificados. Porém, no presente estudo, somente a serapilheira de eucalipto de ciclo curto teve maior teor de lignina (VSC) por unidade de massa de serapilheira, indicando maior recalcitrância desta serapilheira em comparação àquela de acácia, que teve os menores teores de lignina e carboidratos (Tabela 2). A serapilheira da mata nativa e eucalipto de ciclo longo apresentaram teores intermediários destes compostos.

As relações VSC/NeC/Npodem caracterizar bem a qualidade de cada serapilheira; naquelas de eucalipto de ciclo curto e longo (respectivamente E7 e E24) obteve-se valores médios de 8,4 (VSC/N) e $81,2(\mathrm{C} / \mathrm{N})$, e na serapilheira de mata nativa e acácia estes valores foram menores e iguais a $3,8(\mathrm{VSC} / \mathrm{N})$ e 39,8 (C/N) (Tabela 2). Tais resultados indicaram redução da relação $\mathrm{VSC} / \mathrm{N}$ e $\mathrm{C} / \mathrm{N}$ no cultivo de acácia e na mata nativa em comparação aos cultivos de eucalipto, o que pode favorecer a labilidade da serapilheira e aumentar a presença de compostos orgânicos provenientes da atividade microbiana na MOS. Garay et al. (2004) e Forrester et al. (2006) relataram que a adoção de técnicas de manejo, como a rotação de cultivos do eucalipto com espécies fixadoras de $\mathrm{N}_{2}$, ou o cultivo consorciado com a acácia têm reduzido as relações $\mathrm{C} / \mathrm{N}$, lignina/ $\mathrm{N}$, lignina/carboidratos na serapilheira, entre outras, podendo aumentar sua labilidade, e favorecer a estocagem de $\mathrm{C}$ e N na MOS, e nesta condição, o solo atuaria como dreno de $\mathrm{C}$ e nutrientes provenientes de resíduos parcialmente decompostos (derivados de lignina, hemicelulose, etc.) e de produtos da atividade microbiana (proteínas, aminoaçúcares, compostos orgânicos de baixo peso molecular, etc.).

Corroborando com resultados obtidos por Garay et al. (2004) e Forrester et al. (2006), neste trabalho, o cultivo rotacionado de acácia após o eucalipto de ciclo curto, aumentou o teor de $\mathrm{C}\left(13,43 \mathrm{~g} \mathrm{~kg}^{-1}\right), \mathrm{N}\left(1,20 \mathrm{~g} \mathrm{~kg}^{-1}\right)$ e carboidratos (4.114 $\mathrm{mg} \mathrm{kg}^{-1}$ ) na camada de 0,00-0,10 $\mathrm{m}$ de solo em comparação à monocultura de eucalipto em ciclo curto $\left(\mathrm{C}=8,49 \mathrm{~g} \mathrm{~kg}^{-1} ; \mathrm{N}=0,84 \mathrm{~g} \mathrm{~kg}^{-1} \mathrm{e}\right.$ carboidratos $=$ $\left.3.373 \mathrm{mg} \mathrm{kg}^{-1}\right)$, aproximando-se dos teores obtidos no solo na condição original (mata nativa) (Tabela $3)$.

Além do incremento de $\mathrm{C}$ verificado no solo com acácia, no eucalipto de ciclo longo 
TABELA 2: Estoque de matéria seca total (MS), percentagem de resíduos grossos-RG (galhos grossos, com diâmetro $>5 \mathrm{~mm}$ ) e resíduos finos-RF (folhas+galhos finos, com diâmetro $<5 \mathrm{~mm}+$ casca), teores médios de carbono $(\mathrm{C})$ e nitrogênio $(\mathrm{N})$, carboidratos totais (Carb), fenóis derivados de lignina (VSC) e relações $\mathrm{C} / \mathrm{N}, \mathrm{VSC} / \mathrm{N}$ e VSC/Carb na serapilheira de mata nativa (MN), eucalipto de ciclo longo (E24), acácia (A) e eucalipto de ciclo curto (E7) dos Tabuleiros Costeiros do Espírito Santo.

TABLE 2: Dry matter stock (MS), coarse litter percentage-RG (coarse branches with diameter $>5 \mathrm{~mm}$ ) and fine litter percentage-RF (leaves + fine branches with diameter $<5 \mathrm{~mm}$ and bark), carbon concentration mean $(\mathrm{C})$ and total nitrogen $(\mathrm{N})$, carbohydrate (Carb), lignin-derived phenols (VSC) and $\mathrm{C} / \mathrm{N}, \mathrm{VSC} / \mathrm{N}, \mathrm{VSC} / \mathrm{Carb}$ ratios in litter of native forest (MN), eucalyptus long-cycle (E24), acacia (A) and eucalyptus short-cycle (E7) of the coastal plains of Espírito Santo state.

\begin{tabular}{|c|c|c|c|c|c|c|c|c|c|}
\hline \multirow[t]{2}{*}{ Cultivo } & MS & $\mathrm{RG}$ & $\mathrm{RF}$ & $\mathrm{C}$ & $\mathrm{N}$ & VSC & Carb & \multirow[t]{2}{*}{$\mathrm{C} / \mathrm{N}$} & \multirow[t]{2}{*}{$\mathrm{VSC} / \mathrm{N}$} \\
\hline & --t ha-1-- & \multicolumn{2}{|c|}{---------\%"-------' } & \multicolumn{4}{|c|}{ 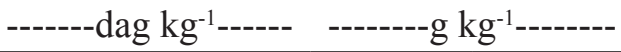 } & & \\
\hline $\mathrm{MN}$ & $6,0 \mathrm{~d}$ & $14,0 \mathrm{c}$ & $86,0 \mathrm{a}$ & $48,6 \mathrm{a}$ & $1,3 \mathrm{a}$ & $51,6 \mathrm{~b}$ & $520,5 \mathrm{a}$ & $36,8 b$ & $3,9 b$ \\
\hline E24 & $12,4 \mathrm{c}$ & $32,0 \mathrm{~b}$ & $68,0 \mathrm{~b}$ & $48,9 \mathrm{a}$ & $0,6 \mathrm{~b}$ & $51,6 \mathrm{~b}$ & $507,0 \mathrm{a}$ & $84,2 \mathrm{a}$ & $8,9 \mathrm{a}$ \\
\hline $\mathrm{A}^{1}$ & $26,2 b$ & $64,0 \mathrm{a}$ & $36,0 \mathrm{c}$ & $48,4 \mathrm{a}$ & $1,1 \mathrm{a}$ & $42,3 b$ & $399,2 b$ & $42,8 b$ & $3,7 \mathrm{~b}$ \\
\hline $\mathrm{E} 7^{1}$ & $66,9 a$ & $71,0 \mathrm{a}$ & $29,0 \mathrm{c}$ & $46,9 \mathrm{a}$ & $0,6 \mathrm{~b}$ & $69,2 \mathrm{a}$ & $560,0 \mathrm{a}$ & $78,2 \mathrm{a}$ & $7,8 \mathrm{a}$ \\
\hline CV $(\%)$ & 10,0 & 23,8 & 19,8 & 2,8 & 13,2 & 17,1 & 12,4 & 35,9 & 50,0 \\
\hline
\end{tabular}

Em que: Médias seguidas da mesma letra, minúscula na coluna, não diferem entre si a $5 \%$ pelo teste LSD de Fisher protegido; ${ }^{1}=$ Incluem resíduos da última colheita.

TABELA 3: Teores médios de carbono orgânico (C) e nitrogênio total $(\mathrm{N})$, carboidratos totais (Carb), fenóis derivados de lignina (VSC), aminoaçúcares (Amino) e relações C/N, VSC/N e VSC/ Carb no solo de mata nativa (MN), eucalipto de ciclo longo (E24), acácia (A) e eucalipto de ciclo curto (E7) dos Tabuleiros Costeiros do Espírito Santo.

TABLE 3: Organic carbon concentration mean (C) and total nitrogen $(\mathrm{N})$, total carbohydrates (Carb), lignin-derived phenols (VSC), amino sugars (amino) and $\mathrm{C} / \mathrm{N}, \mathrm{VSC} / \mathrm{N}, \mathrm{VSC} / \mathrm{Carb}$ ratios in soil of native forest (MN), eucalyptus long-cycle (E24), acacia (A) and eucalyptus short-cycle (E7) of the coastal plains of Espírito Santo state.

\begin{tabular}{|c|c|c|c|c|c|c|c|}
\hline \multirow[t]{2}{*}{ Cultivo } & $\mathrm{C}$ & $\mathrm{N}$ & VSC & Carb & Amino & \multirow[t]{2}{*}{$\mathrm{C} / \mathrm{N}$} & \multirow[t]{2}{*}{$\mathrm{VSC} / \mathrm{N}$} \\
\hline & \multicolumn{2}{|c|}{----------g kg kg $^{-1}-{ }^{------}$} & \multicolumn{3}{|c|}{ 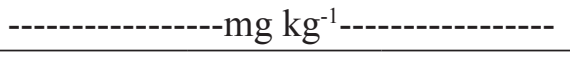 } & & \\
\hline $\mathrm{MN}$ & $17,5 \mathrm{a}$ & $1,3 \mathrm{a}$ & $141,4 \mathrm{a}$ & $5004,3 \mathrm{a}$ & $480,9 \mathrm{a}$ & $13,5 \mathrm{a}$ & $0,11 \mathrm{a}$ \\
\hline E24 & $11,9 \mathrm{c}$ & $0,9 b$ & $65,1 b$ & $3566,6 b c$ & $306,9 \mathrm{c}$ & $13,2 \mathrm{a}$ & $0,07 \mathrm{~b}$ \\
\hline A & $13,4 b$ & $1,2 \mathrm{a}$ & $141,0 \mathrm{a}$ & $4113,5 b$ & $406,5 b$ & $11,7 \mathrm{a}$ & $0,12 \mathrm{a}$ \\
\hline E7 & $8,5 \mathrm{~d}$ & $0,8 b$ & $105,7 \mathrm{ab}$ & $3372,9 \mathrm{c}$ & $379,1 b$ & $10,6 \mathrm{a}$ & $0,13 \mathrm{a}$ \\
\hline $\mathrm{CV}(\%)$ & 5,6 & 13,6 & 13,8 & 10,7 & 10,8 & 16,4 & 15,9 \\
\hline
\end{tabular}

Em que: Médias seguidas da mesma letra, minúscula na coluna, não diferem entre si a $5 \%$ pelo teste LSD de Fisher protegido.

(E24) obteve-se aumento do teor de C no solo em relação ao eucalipto de ciclo curto, isto indica que o aumento do tempo de cultivo sem revolvimento do solo, favoreceu o estoque de C. O não revolvimento e exposição do solo pelas atividades da colheita e preparo do sítio para novo cultivo na área de eucalipto de longa rotação pode ter reduzido a taxa de mineralização da MOS. Adicionalmente, no E24 verificou-se a maior presença de sub-bosque, o que pode ter beneficiado a MOS pelo aporte de C via resíduos de qualidade distinta daquela de resíduos de eucalipto. Shan et al. (2001) demonstraram em povoamentos de Pinus com manutenção de subbosque que houve efeito positivo na manutenção da MOS e, Schiavo et al. (2009) observaram melhoria dos atributos químicos e biológicos do solo com o aumento do tempo de cultivo do eucalipto, para a cromossequência de três, cinco e doze anos após 
o plantio na região de Campos do Goitacazes, Rio de Janeiro. No entanto, no solo cultivado com E24 obteve-se menor teor de lignina na camada de 0,00 $0,10 \mathrm{~m}$ em comparação àqueles de acácia e mata nativa (Tabela 3 ). Supõe-se que o maior tempo de cultivo do eucalipto ( 24 anos) em comparação ao solo com acácia (14 anos), e a maior relação $\mathrm{C} / \mathrm{N}$ e VSC/N na serapilheira do E24 em comparação àquela de mata nativa, sejam fatores preponderantes para obtenção de tais resultados. Segundo Pegoraro et al. (2011b) a presença de resíduos grossos na serapilheira de eucalipto indicou maior teor de grupamentos fenólicos derivados na lignina, maior relação $\mathrm{VSC} / \mathrm{N}(8,7)$ e C/N $(93,0)$, evidenciando menor labilidade da serapilheira de eucalipto e possível retardamento do processo de decomposição microbiana em comparação aos resíduos finos de eucalipto. Contudo, deve-se ressaltar que no solo cultivado com eucalipto de ciclo longo o sistema radicular de muitas plantas permaneceu vivo, o que pode ter reduzido o aporte de lignina e a relação $\mathrm{VSC} / \mathrm{N}$ após 24 anos de cultivo. Outro fator que pode ter contribuído para tal resultado foi a menor densidade de árvores do eucalipto de ciclo longo devido aos desbastes (iniciou com 1.111 plantas $\mathrm{ha}^{-1}$ e, no momento da amostragem de solo, contou com aproximadamente 300 plantas ha $\mathrm{p}^{-1}$ ).

Os resíduos grossos de eucalipto (E7 e E24) apresentaram maior teor de lignina (VSC) do que naqueles da serapilheira de mata nativa e acácia, em decorrência do maior teor de compostos do grupamento siringil (Figura 1). Os resíduos finos da serapilheira de mata nativa apresentaram a maior relação ácido/aldeído nos grupamentos vanilil e siringil em comparação àqueles de cultivos de eucalipto e acácia e aos resíduos grossos da serapilheira de mata nativa (Figura 1), indicando o maior estádio de decomposição de resíduos finos na mata nativa. No entanto, a relação média ácido/ aldeído nos resíduos grossos e finos da serapilheira dos cultivos foi menor que 0,5 , o que indica a predominância de aldeídos nos grupamentos siringil e vanilil, ou seja, a serapilheira encontra-se num estado menos alterado que a MOS.

No solo, o estado mais avançado de decomposição dos compostos derivados da lignina em comparação à serapilheira resultou na maior abundância de monômeros com grupamentos ácidos, como o ácido vanílico (25\%), ácido siríngico $(12 \%)$ e ácido ferúlico (10 \%) (Figura 2). Comparando-se os teores de fenóis obtidos na serapilheira com aqueles do solo, entre os cultivos, verificou-se que a maior abundância de resíduos grossos e lignina da serapilheira de eucalipto de ciclo curto (Tabela 2) não garantiu maior acúmulo de lignina no solo (Tabela 3 ), pois maiores teores de siringaldeído e ácido siríngico foram obtidos no solo da mata nativa e de acácia. Esses resultados indicam menor labilidade e, ou, maior dificuldade na incorporação destes fenóis dos resíduos lenhosos de eucalipto em MOS.

No solo de eucalipto de ciclo curto, o aumento da deposição de resíduos grossos na serapilheira pode ter favorecido a produção de enzimas microbianas decompositoras de compostos orgânicos polimerizados e bioquimicamente complexos, de forma não muito seletiva. Segundo Fontaine et al. (2003) numa condição de menor qualidade de substrato (resíduos vegetais), parte da MOS humificada pode ser utilizada como fonte de energia e nutrientes pelos microrganismos heterotróficos, o que implicaria na redução no teor de lignina no solo. Heim e Shimidt (2007) observaram que o tempo médio de residência de lignina no solo (5 a 26 anos para pastagens e $<9$ a 38 anos para solos cultivados com Miscanthus giganteus, planta perene utilizada pela indústria como fonte de energia e celulose) pode ser menor que aquele do $\mathrm{C}$ orgânico no solo (20 a 26 anos para pastagens e 51 anos para solos cultivados com Miscanthus giganteus), indicando que a lignina no solo não será, necessariamente, preservada e pode ser utilizada como fonte de energia para microrganismos heterotróficos decompositores, principalmente quando o substrato (serapilheira) for de menor qualidade (menor teor de compostos orgânicos lábeis).

No entanto, as maiores relações $\mathrm{Ac} / \mathrm{Al}$ no grupamento vanilil da lignina foram observadas no solo de mata nativa e acácia (Figura 2). Nestes solos, as relações $\mathrm{Ac} / \mathrm{Al}$ do grupamento vanilil foram maiores do que 2,5, indicando a predominância de grupamentos ácidos e estádio mais avançado de degradação/oxidação da lignina que nos solos de eucalipto. Tais resultados podem estar associados à maior atividade microbiana decompositora no solo de mata nativa e acácia, estimulada pela maior qualidade dos resíduos vegetais e indicada pelo maior teor de aminoaçúcares (Figura 1).

Mesmo com o aumento da atividade microbiana decompositora, suportada pela maior abundância de seus produtos, no solo de rotação de acácia foram observados maiores teores de $\mathrm{C}$ e $\mathrm{N}$ em relação àqueles sob monocultivo de eucalipto 

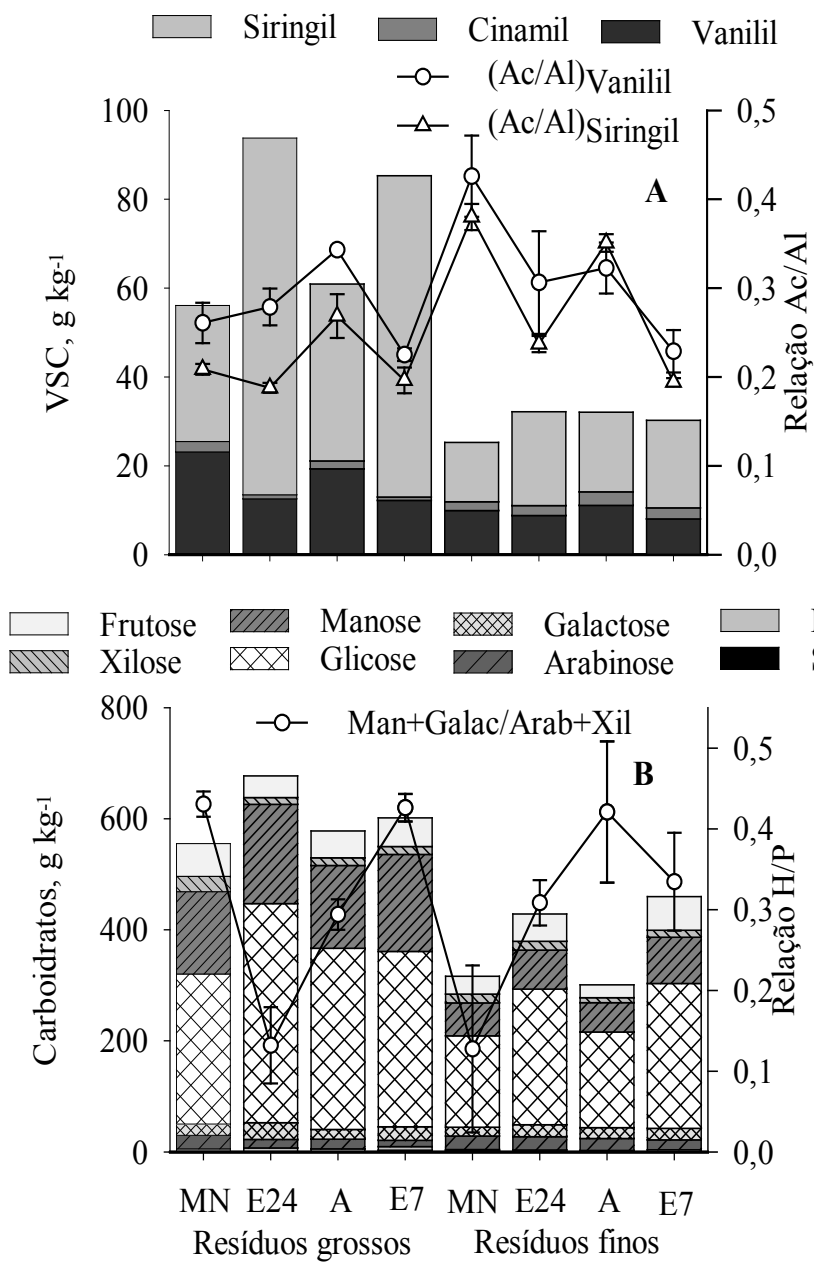

FIGURA 1: Teor médio de fenóis derivados de lignina (VSC: Vanilil, Siringil e Cinamil) e carboidratos nos resíduos grossos e resíduos finos da serapilheira de mata nativa (MN), eucalipto de ciclo longo (E24), acácia (A) e eucalipto de ciclo curto (E7). A. relação ácido/aldeído (Ac/Al) nos derivados vanilil e siringil e B. relação H/P (relação entre hexoses (manose+galactose) e pentoses (glucose+xilose)). Linhas verticais indicam erro padrão da média $(\mathrm{n}=3)$.

FIGURE 1: Lignin-derived phenols content mean (VSC: vanilil, syringyl and cinnamyl) and carbohydrates in coarse and fine litter from native forest (MN), eucalyptus long-cycle (E24), acacia (A) and eucalyptus short-cycle (E7). A. acid/aldehyde ratio (Ac/Al) in vanilil and syringyl derivatives and B. H/P ratio (ratio of hexoses (mannose + galactose) and pentoses (glucose + xylose)). Vertical lines indicate standard error of mean $(n=3)$.

(Tabela 3), indicando que houve incremento na MOS, mas ainda inferior à condição original do solo (mata nativa). No solo de acácia, em comparação aos de eucalipto, os produtos intermediários derivados de estruturas microbianas podem estar sendo estabilizados mais eficientemente devido à maior formação de complexos com a fração argila do solo (argilo-orgânicos), ricos em compostos alifáticos decorrentes da atividade microbiana. Produtos da atividade microbiana são estabilizados quimicamente no solo pela sua alta interação com partículas de argila e pela oclusão física causada pela formação de agregados (SIX et al., 2006). Quanto maior a presença destes compostos no solo, possivelmente, maior será a agregação e sua preservação, aumentando os estoques de $\mathrm{C}$ e $\mathrm{N}$ no solo.

Efeitos positivos da maior presença de $\mathrm{N} \mathrm{e}$, possivelmente, da diversidade ecológica e biológica no cultivo de acácia e na mata nativa também podem ser considerados fatores preponderantes para o aumento da presença de compostos orgânicos derivados da atividade microbiana, da estabilização e dos estoques de $\mathrm{C}$ nos solos. $\mathrm{O}$ efeito positivo do $\mathrm{N}$ 

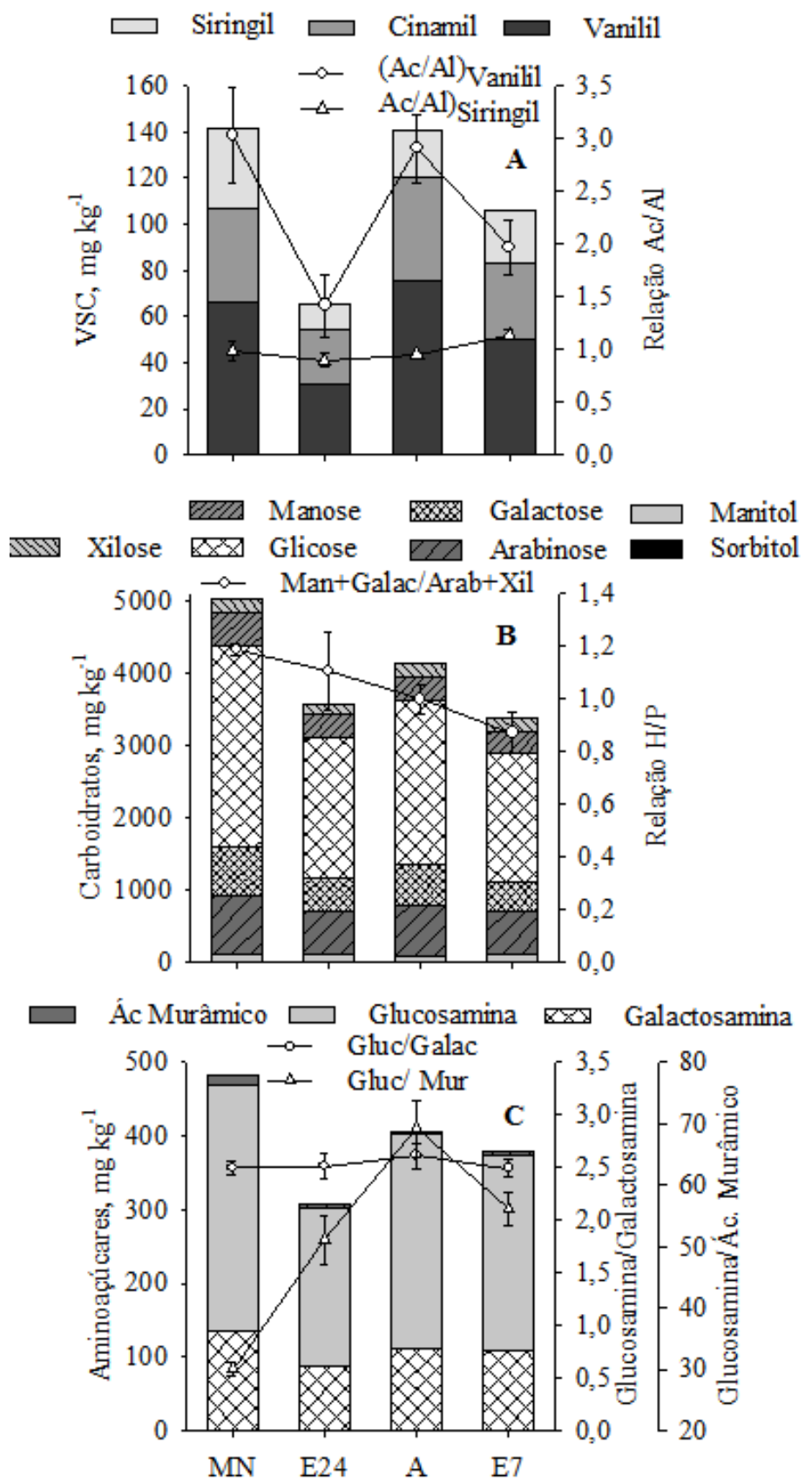

FIGURA 2: Teor de fenóis derivados de lignina (VSC: Vanilil, Siringil e Cinamil), carboidratos e aminoaçúcares em amostras de solo (camada de 0-10 cm) coletadas em mata nativa $(\mathrm{MN})$, eucalipto de ciclo longo (E24), acácia (A) e eucalipto de ciclo curto (E7). A: relação ácido/ aldeído (Ac/Al) nos derivados vanilil e siringil; B: relação H/P (relação entre hexoses (manose+galactose) e pentoses (glucose+xilose)) e C: aminoaçúcares derivados da comunidade fúngica (glucosamina) em relação a compostos bacterianos (ácido murâmico). Linhas verticais indicam erro padrão da média $(\mathrm{n}=3)$.

FIGURE 2: Lignin-derived phenols content mean (VSC: vanilil, syringyl and cinnamyl), carbohydrates and amino sugars in soil samples $(0-10 \mathrm{~cm})$ collected in native forest $(\mathrm{MN})$, eucalyptus longcycle (E24), acacia (A ) and eucalyptus short-cycle (E7). A. acid/aldehyde ratio (Ac/Al) in syringyl and vanilil derivatives, B. H/P - hexoses (mannose + galactose) and pentoses ratio (glucose + xylose) and C. derived amino sugar from fungal community (glucosamine) in relation to bacterial compounds (muramic acid). Vertical lines indicate standard error of mean $(\mathrm{n}=3)$. 
no aumento da estabilização do C do solo em longo prazo está associado à sua incorporação à estrutura das substâncias húmicas, as quais são recalcitrantes (STEVENSON, 1994). A redução da relação $\mathrm{C} / \mathrm{N}$ de resíduos vegetais de palha de arroz pela adubação com $\mathrm{N}$ mineral no solo favoreceu o acúmulo de $\mathrm{C}$ na fração humina (compartimento das substâncias húmicas mais resistente à oxidação) e o aumento do teor da MOS (MORAN et al., 2005). Sjöberg et al. (2004) destacam que a estabilização estrutural pode ocorrer devido à reação do $\mathrm{N}$ com resíduos de lignina e compostos fenólicos, seguido pela formação de compostos recalcitrantes, como um complexo tanino-proteína. Neste sentido, mesmo espécies com maior teor de lignina na serapilheira proveniente de raízes somente aumentaram a estabilidade de $\mathrm{C}$ refratário no solo em relação a espécies com baixo conteúdo de lignina na serapilheira quando o $\mathrm{N}$ inorgânico foi adicionado $\left(4 \mathrm{~g} \mathrm{~m}^{-2} \mathrm{ano}^{-1}\right)$ na camada de 0,00-0,10 m de solo (DIJKSTRA et al., 2004). Neste estudo, o teor de lignina foi maior no solo de acácia e mata nativa, onde os teores de $\mathrm{N}$ também foram superiores àqueles obtidos nos cultivos de eucalipto (Tabela 3), mesmo não tendo apresentado maiores teores de lignina na serapilheira (Tabela 2).

No solo sob monocultivo de eucalipto de ciclo curto obteve-se o menor teor de carboidratos totais e, um decréscimo da relação H/P (man + galac/ $\mathrm{arab}+$ xil < 1,0) em comparação àquele em rotação com acácia e ao solo sob mata nativa (Figura 2), evidenciando a menor conversão de carboidratos da serapilheira em derivados de C mais estáveis no solo (hexoses ou pentoses) e, maior proporção de polímeros de pentose provenientes da atividade microbiana em comparação ao solo sob rotação de acácia e mata nativa.

Dentre os aminoaçúcares (glucosamina, galactosamina) e ácido murâmico, quantificados no solo, notou-se em todos os tratamentos maior teor de glucosamina (Figura 2). Esse resultado pode ter ocorrido pela maior síntese microbiana (fungos, bactérias e actinomicetos produzem esse composto em diferentes quantidades) e estabilidade da glucosamina no solo. A glucosamina pode ser originada de vários microrganismos no solo (GLASER et al., 2004), mas resultados observados em literatura caracterizam a glucosamina como aminoaçúcar originado principalmente da atividade fúngica no solo (ZHANG et al., 1998; SOLOMON et al., 2002). Acredita-se que os fungos são iniciadores do processo de decomposição da serapilheira e os principais responsáveis pela decomposição de compostos mais recalcitrantes da MOS (FONTAINE et al., 2003). Deste modo, sua atividade e presença de seus derivados (aminoaçúcares, entre outros) no solo, tendem a ser maior do que aquela de bactérias (LIANG et al., 2007). A maior estabilidade da glucosamina nestes solos em relação à galactosamina e ácido murâmico é justificada pela sua constituição em glomalina, uma glicoproteína recalcitrante produzida no solo por fungos micorrízicos arbusculares (ZHANG et al., 1998).

$\mathrm{Na}$ comparação entre os usos florestais, os solos de rotação com acácia seguidos daquele cultivado com eucalipto de ciclo curto foram os que apresentaram maior relação glucosamina/ ácido murâmico ( $\approx 68$ e 56 , respectivamente) e o solo da mata nativa foi o que teve menor relação $(\approx 30)$ (Figura 2), indicando a maior proporção de aminoaçúcares provenientes principalmente da atividade fúngica no solo cultivado com acácia e eucalipto. Este resultado pode estar relacionado à maior proporção de resíduos grossos e teor de lignina na serapilheira de acácia e eucalipto, o que propiciaria a proliferação de fungos responsáveis pela decomposição específica de lignina e liberação de glucosamina no solo.

A maior relação glucosamina/ácido murâmicoa verificada no solo de acácia pode ter implicação prática na estocagem de $\mathrm{C}$ e agregação do solo. Segundo Bailey et al., (2002) e Simpson et al. (2004), maior atividade fúngica também pode significar maior grau de agregação interna entre micro e macroagredados do solo devido aos compostos orgânicos advindos da sua atividade, resultando em maior conservação ou acúmulo de $\mathrm{C}$ em sistemas conservacionistas de solo. Estudos desta ordem podem facilitar o entendimento da formação da matéria orgânica em solos florestais tropicais, tornando possível a adoção de técnicas de manejo que contribuam para a manutenção da MOS. A recuperação na qualidade do solo cultivado anteriormente com eucalipto de ciclo curto pelo cultivo da acácia também refletiu na abundância e distribuição desses biomarcadores, e certamente é merecedora de estudos adicionais.

\section{CONCLUSÕES}

A serapilheira do monocultivo de eucalipto de ciclo curto apresenta maior deposição da matéria seca, teor de lignina (VSC) e carboidratos, relação $\mathrm{C} / \mathrm{N}$ e $\mathrm{VSC} / \mathrm{N}$; proporção semelhante de resíduos 
grossos, resíduos finos e teor de $\mathrm{C}$ e; menor teor de $\mathrm{N}$, comparado àquela sob rotação de acácia.

O solo cultivado com acácia apresenta maiores teores de $\mathrm{C}, \mathrm{N}$ e carboidratos, aumenta a relação ácido/aldeído do grupamento vanilil da lignina e a relação glucosamina/ácido murâmico dos aminoaçúcares derivados da atividade microbiana, em comparação ao monocultivo de eucalipto de ciclo curto.

O cultivo de eucalipto de ciclo longo (24 anos) incrementa o teor de $\mathrm{C}$ e reduz a relação VSC/N na MOS, em comparação ao monocultivo de eucalipto de ciclo curto, mas ainda apresenta teor de $\mathrm{C}$ e $\mathrm{N}$ inferiores àqueles observados no solo de acácia e mata nativa.

A serapilheira e o solo de eucalipto (ciclo curto e ciclo longo) obtêm menor relação Ac/Al do grupamento vanilil de fenóis derivados da ligninado em relação àqueles de acácia e mata nativa.

O cultivo da acácia seguido pelo de eucalipto de ciclo curto, aumenta a relação glucosamina/ ácido murâmico, o que indica maior proporção de aminoaçúcares provenientes principalmente da atividade fúngica nestes solos, em comparação àqueles de mata nativa e eucalipto de ciclo longo.

\section{AGRADECIMENTOS}

À FAPEMIG e ao CNPq pelo apoio financeiro. À empresa florestal Aracruz, pela disponibilização da área experimental para realização do estudo.

\section{REFERÊNCIAS BIBLIOGRÁFICAS}

AMELUNG, W. et al. Neutral and acidic sugars in particle-size fractions as influenced by climate. Soil Science Society of America Journal, Madison, v. 63, n. 4, p. 865-873, 1999.

BAILEY, V. L. et al. Fungal-to-bacterial ratios in soils investigated for enhanced $\mathrm{C}$ sequestration. Soil Biology and Biochemical, Oxford, v. 34, n. 7, p. 997-1007, 2002.

BATAGLiA, O. C. et al. Métodos de análises químicas de plantas. Campinas: Instituto Agronômico, 1983. 48p. (Boletim, 78)

CARREIRO, M. M. et al. Microbial enzyme shifts explain litter decay responses to simulated nitrogen deposition. Ecology, Washington, v.81, n. 9, p. 2359-2365, 2000.

DIJKSTRA, F. A. et al. Nitrogen deposition and plant species interact to influence soil carbon stabilization. Ecology Letters, Oxford, v. 7, n. 12, p. 1192-1198, 2004.

EMBRAPA, Centro Nacional de Pesquisa de Solos. Manual de métodos de analise de solo. 2. ed. Rio de Janeiro, 1997. 212 p.

EMBRAPA. Centro Nacional de Pesquisa de Solos. Sistema brasileiro de classificação de solos. 2. ed. Rio de Janeiro, 2006. 306 p.

FOG, K. The effect of added nitrogen on the rate of decompositionoforganicmatter.BiologicalReviews, v. 63, n. 3, p. 433-462, 1988.

FONTAINE, S. et al. The priming effect of organic matter: a question of microbial competition? Soil Biology and Biochemical, Oxford, v. 35, n. 6, p.837-843, 2003.

FORRESTER, D.I. et al. Carbon allocation in a mixed-species plantation of Eucalyptus globulus and Acacia mearnsii. Forest Ecology and Management, Amsterdam, v. 233, n. 2-3, p. 275284, 2006.

FUNDAÇÃO ARTHUR BERNARDES FUNARBE. SAEG - Sistema para análise estatística 5.0. Viçosa, 1993.

GARAY, I. et al. Evaluation of soil conditions in fast-growing plantations of Eucalyptus grandis and Acacia mangium in Brazil: a contribution to the study of sustainable land use. Applied Soil Ecology, Madison, v. 27, n. 2, p. 177-187, 2004.

GLASER, B. et al. Amino sugars and muramic acidbiomarkers for soil microbial community structure analysis. Soil Biology and Biochemical, Oxford, v. 36, n. 3, p. 399-407, 2004.

GOÑI, M. A.; MONTGOMERY, S. Alcaline CuO oxidation with a microwave digestion system: lignin analyses of geochemical samples. Analytical Chemistry, v. 72, n. 14, p. 3116-3121, 2000.

HEDGES, J. I.; ERTEL. J. R. Characterization of lignin by gas capillary chromatography of cupric oxide products. Analytical Chemistry, v. 54, n. 2, p. 174-178, 1982.

HEIM, A.; SCHMIDT, M. W. I. Lignin turnover in arable soil and grassland analysed with two different labelling approaches. European Journal of Soil Science, Oxford, v. 58, n. 3, p. 599-608, 2007.

LEMMA, B. et al. Decomposition and substrate quality of leaf litters and fine roots from three exotic plantations and a native forest in the southwestern highlands of Ethiopia. Soil Biology and Biochemical, Oxford, v. 39, n. 9, p. 2317-2328, 2007.

LIANG, C. et al. Effect of plant materials on microbial transformation of amino sugars in three 
soil microcosms. Biology and Fertility of Soils, Berlin, v. 43, n. 6, p. 631-639, 2007.

MARTENS, D. A.; LOEFFELMANN, K. L. Improved accounting of carbohydrate carbon from plants and soils. Soil Biology and Biochemical, Oxford, v. 34, n. 10, p. 1393-1399, 2002.

MENDHAM, D. S. et al. Soil particulate organic matter effects on nitrogen availability after afforestation with Eucalyptus globules. Soil Biology and Biochemical, Oxford, v. 36, n. 1, p. 1067-1074, 2004.

MÖLLER, A. et al. Lignin, carbohydrate, and amino sugar distribution and transformation in the tropical highland soils of northern Thailand under cabbage cultivation, Pinus reforestation, secondary forest, and primary forest. Australian Journal of Soil Research, Collingwood, v. 40, n. 6, p. 977-998, 2002.

MORAN, K. K. et al. Role of mineral-nitrogen in residue decomposition and stable soil organic matter formation. Soil Science Society of America Journal, Madison, v. 69, n. 6, p. 1730-1736, 2005. OLK, D. C. et al. Impaired cycling of soil nitrogen under continuous rice rotations in the Arkansas Grand Prairie area. In: RICE TECHNICAL WORKING GROUP, 13., 2004, New Orleans. Proceedings... Louisiania: State University Agricultural Center, 2004. p. 148-149

OMETTO, J. C. Bioclimatologia vegetal. São Paulo, Ceres, 1981. 425 p.

OTTO, A.; SIMPSON, M. J. Evaluation of $\mathrm{CuO}$ oxidation parameters for determining the source and stage of lignin degradation in soil. Biogeochemistry, Heidelberg, v. 80, n. 2, p. 121-142, 2006.

PEGORARO, R. F. et al. Estoques de carbono e nitrogênio em frações da matéria orgânica de solos cultivados com eucalipto nos sistemas convencional e fertirrigado. Ciência Rural. Santa Maria, v. 40, n. 2, p. 272-279, 2010.

PEGORARO, R. F. et al. Estoques de carbono e nitrogênio nas frações da matéria orgânica em argissolo sob eucalipto e pastagem. Ciência Florestal, Santa Maria, v. 21, n. 2, p. 261-273, 2011a.

PEGORARO, R. F. et al. Fenóis derivados da lignina, carboidratos e aminoaçúcares em serapilheira e solos cultivados com eucalipto e pastagem. Revista Árvore. Viçosa, v. 35, n. 2, p. 359-370, 2011 b.

PILLON, C. N. et al. Carbono e nitrogênio de um Argissolo Vermelho sob floresta, pastagem e mata nativa. Ciência Rural. Santa Maria, v. 41, n. 3, p. 447-453. 2011.
RASSE, D. P. et al. Lignin turnover in an agricultural field: from plant residues to soil-protected fractions. European Journal of Soil Science, Oxford, v. 57, n. 4, p. 530-538, 2006.

SCHIAVO, J. A. et al. Recovery of degraded areas revegeted with Acacia mangium and Eucalyptus with special reference to organic matter humification. Sciencia Agricola, Piracicaba, v. 66, n. 3, p. 353-360, 2009.

SHAN, J. et al. The effects of management on soil and plant carbon sequestration in slash pine plantations. Journal of Applied Ecology, Oxford, v. 38, n. 5, p. 932-941, 2001.

SIMPSON, R. T. et al. Preferential accumulation of microbial carbon in aggregate structures of no-tillage soils. Soil Science Society of America Journal, Madison, v. 68, n. 4, p. 1249-1255, 2004. SIX, J.; et al. Bacterial and fungal contributions to carbon sequestration in agroecosystems. Soil Science Society of America Journal, Madison, v. 70, n. 2, p. 555-569, 2006.

SJÖBERG, G. et al. Degradation of hemicellulose, cellulose and lignin in decomposing spruce needle litter in relation to N. Soil Biology and Biochemical, Oxford, v. 36, n. 11, p. 1761-1768, 2004.

SOLOMON, D. et al. Land use effects on amino sugar signature of chromic Luvisol in the semiarid part of northern Tanzania. Biology and Fertility of Soils, Berlin, v. 33, n. 1, p. 33-40, 2001. SOLOMON, D. et al. Soil organic matter composition in the subhumid Ethiopian highlands as influenced by deforestation and agricultural management. Soil Science Society of America Journal, Madison, v. 66, n. 1, p. 68-82, 2002.

STEEL, R. G. D. et al. Principles and procedures of statistics: a biometrical approach. New York: McGraw-Hill, 1997. 666 p.

STEVENSON, F. J. Humus Chemistry: Genesis, Composition and Reactions. $2^{\mathrm{ND}}$ ed. New York, Willey \& Sons Inc., 1994. 496 p.

SUHAS, P. J. M. C.; CARROTT, M. M. L. R. Lignin - from natural adsorbent to activated carbon: A review. Bioresource Technology, v. 98, n. 12, p.2301-2312, 2007.

YEOMANS, J. C.; BREMNER, J. M. A rapid and precise method for routine determination of organic carbon in soil. Communications in Soil Science and Plant Analysis, Philadelphia, v. 13, n. 13, p. 1467-1476, 1988.

ZHANG, $X$. et al. Amino sugar signatures of particle size fractions in soils of the native prairie as affected by climate. Soil Science, Hagerstown, v. 163, n. 
3, p. 220-229, 1998.

ZHANG, X.; AMELUNG, W. Gas chromatographic determination of muramic acid, glucosamine, mannosamine, and galactosamine in soils. Soil Biology and Biochemical, Oxford, v. 28, n. 3, p. 1201-1206, 1996. 